\title{
INFLUENCE OF TRANSFER MOTIVATION AND TRAINING RETENTION TOWARDS TRAINING TRANSFER ON EMPLOYEE'S PERFORMANCE
}

\author{
Septana Deva*, Umar Husein \\ University of Esa Unggul, Tangerang, Indonesia \\ *E-mail: dseptana@gmail.com
}

\begin{abstract}
The objectives of this research can be arranged consistently to answer the formulation of research problems, which are to know the perception of the participant's preparation that influences the transfer motivation on the training transfer; to know the perception of the colleagues' supports that influence the transfer motivation on the training transfer; to know the perception of the employer's supports that influence the transfer motivation on the training retention. The research method used in this research is conclusive research design, in which this research is a type of research that aims to test the hypothesis associated with various variables. The results of this study are: transfer motivation has a positive influence on training transfer, where strong self-motivation, support from employer, and colleagues can increase the activity of training transfer in the workplace. This gives an influence on improving employee's performance; training retention in the form of reward both intrinsic reward in the form of praise, appreciation; and extrinsic reward in the form of material or money, career as a reward do not influence positively on the employee's performance in implementing the result of training that they have obtained as one of the ways to improve the ability to achieve the rewards/incentives provided by the organization; training transfer gives a positive influence on employees and organizations in which employees contribute by applying training provided to them to improve employee's performance.
\end{abstract}

\section{KEY WORDS}

Employee's performance, transfer motivation, training retention, training transfer.

One of the activities undertaken in human resource management is getting competent people to fill the organization. Typically, those dealing with this issue are coordinated by the Human Resources Department and other related sections are involved. However, there is an important step that must be taken before accepting a new manpower which is to determine the type or quality of the desired employee to fill the position and details of the quantity that will occupy the position. Thus, the first function or activity in human resource management is to get the right people, both in quality and quantity. After that, the withdrawals of manpower, placement selection, orientation, promotion, and transfer or mutation are done.

The need for skilled workers is a demand that cannot be postponed anymore. In the era of globalization as today, the top management should be more aware that having good human resources must be done continuously. One of the ways is through education and training which are planned in accordance with needs analysis that can produce employees who are reliable, have high competence and added value from the financial perspective. In addition, human resource education and training will be able to accelerate the improvement of knowledge, skills and attitude changes according to the needs of the organization at all levels of employees. With education and training, it will also be able to improve employee's performance which is a function of motivation and ability in completing tasks, responsibilities, or works that they have.

A person's willingness and skills will not be effective at doing things without a clear understanding of what to do and how to do it. One of the fast ways to produce employees who have adequate skills is by providing appropriate planned and continuous education and training programs. A training is successful or effective if the participants can accept and have increased knowledge, skill, and attitude which are appropriate and are given by the appropriate instructor/trainer too, as well as the achievement of improved 
performance/competence of employees. From several studies, one of them is Sulistyohadi (2002) who shows that approximately only $10 \%$ of the investment spent on training has changed the attitude of trainees when they return to the workplace. In many studies, it has been found that the success in the training transfer process itself is influenced by the characteristics of the participants and the characteristics of the work environment. One of the characteristics of the training participants is called personality variables consisting of locus of control and self-efficacy are hypothesized as factors affecting the training transfer process. Similarly, the characteristics of the work environment will be able to influence the training transfer process (Baldwin and Ford, 2008; Smith, et al, 2001, Tziner and Haccoun, 2001; Colquit, et al., 2000).

Crider (2003) mentions the characteristics of internal locus of control, such as like to work hard, have high initiative, always try to find problem solving, try to think as effective as possible, always have perception that effort must be done if success is willing to achieve. While, the characteristics of external locus of control are lack of initiative, have a hope that there is a few correlation between effort and success, lack of effort because they believe that the external factors which control it, and they are lack of searching information to solve the problems.

In training situations, trainees who have strong beliefs, they can control organizational outcomes, such as promotion and salary increase. It can be as an extension of more work that makes it possible to apply the content of training in the work. Individual believing that he is able to conduct and complete the task well because of his own effort can be said that the person has an internal locus of control. Individual who considers that success and failure are due to their surroundings, then it can be said that the person has an external locus of control.

In line with that effort, to align the needs of organizations with human resources at PT. Gandum Mas Kencana, the management continues to evaluate the productivity made by the Training and Development Department in order to fulfill its responsibilities professionally and be able to answer the challenges faced by the organization with the locus of control approach.

Department of Training and Development at PT. Gandum Mas Kencana is a container that is formed to unite the interests of the organization and the people in it by designing and reviewing the needs of the organization as stated in the vision, mission, target, future goals, both short-term and long-term goals, strategy, and organizational culture (core value). The other side should also be able to bring the people who are in the organization, both from knowledge, skills and behavior leading to what has been established by the organization as a standard work in running organizational goals.

The problems that emerged at the Training and Development Department in 2016 published by the Internal Audit Department are findings of infringement in the Corrective Action Report (CAR) based on mistakes included in the five categories: Human (HUM), Facility (FAS), Machine (MES), Environment (LIN), and Method (MET). The report showed that HUM accounted for the biggest mistake of about 21 cases, followed by FAS which has 12 cases, 15 cases of MES, LIN with 11 cases, and MET has 9 cases out of 68 cases.

The objectives of this research can be arranged consistently to answer the formulation of research problems, that are 1) to know the perception of participant preparation that influences transfer motivation in training transfer, 2) to know the perception of colleagues supports that influence transfer motivation in training transfer 3 ) to know the perception of superiors' supports that influence transfer motivation in training retention.

\section{METHODS OF RESEARCH}

This research is a causal research conducted to detect causal relationships in order to know the relationship between two or more variables. Sugiono (2012) stated that with causal research, a theory that functions to explain, to predict, and to control an event can be built. This research is also qualitative with deductive modeling. To illustrate the details of the procedure that will be used in the implementation of this research, a research framework is 
needed to elaborate the information required by a research framework to describe the information needed in solving the research problems.

The research method used in this research is conclusive research design in which this research is a type of research that aims to test the hypothesis associated with various variables. The research process with conclusive research is very formal and structured; the sample used is ordinarily many and is quantitative (Malhotra, 2010). The type of conclusive research used in this research is causal research. Causal research is a research that aims to determine the relationship of a causal cause of something. This research aims to prove the relationship of influencing and being influenced of the variables studied (Malhotra, 2010).

The initial step of this research is pretest to test the questionnaire made to 30 respondents. Furthermore, the sample of questionnaires that have been spread are processed and if they are proven valid and reliable, then the questionnaires are distributed back to the larger respondents to obtain primary data. The researcher will spread the questionnaires to get directly the data obtained and adapted to the measuring instruments used, in this case as many as 200 respondents.

\section{RESULTS AND DISCUSSION}

Structural Model Analysis. It is a model that describes the data structures used in business processes, as long as the structural model analysis presents the logic of the data without showing how data is stored, created, or manipulated so that the analyst can focus on the business.

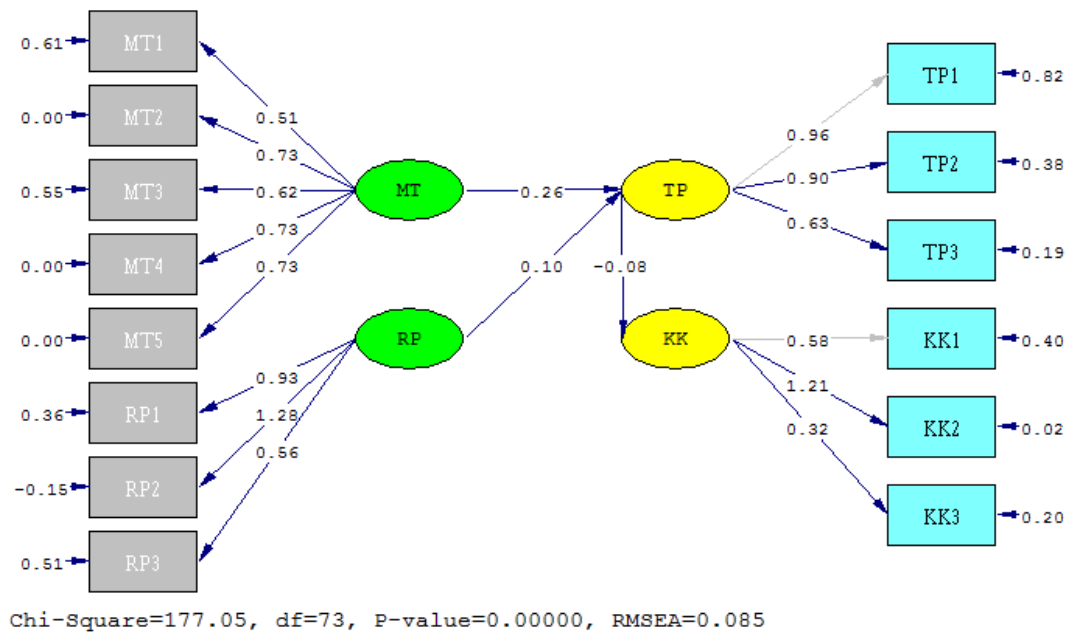

Figure 1 - Structural Equation Model - Estimation

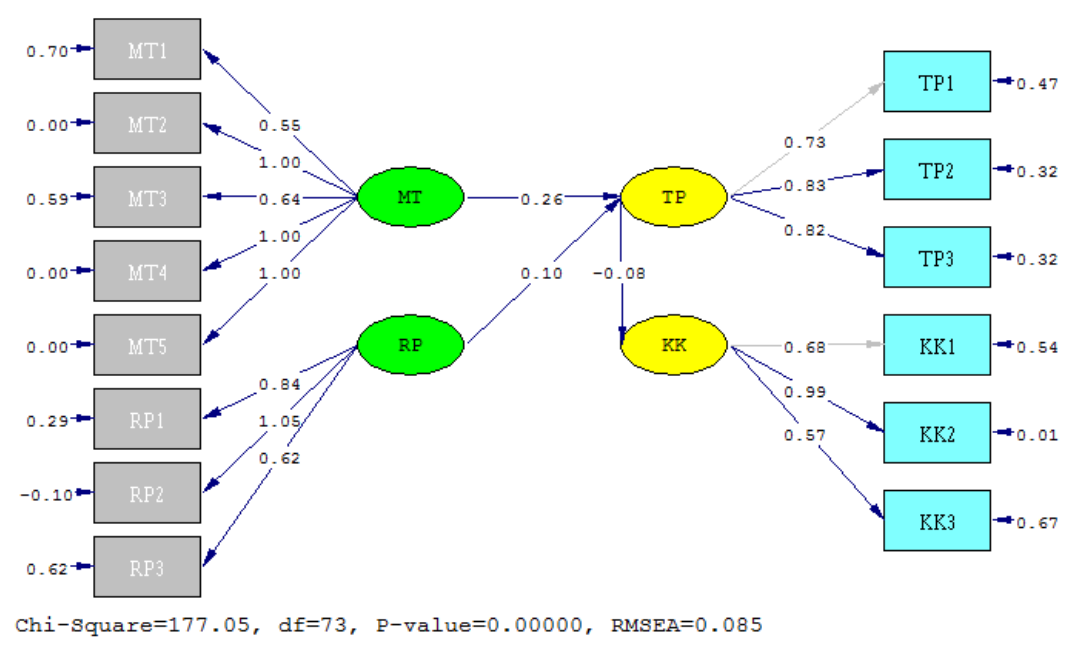

Figure 2 - Structural Equation Model - Standardized Solution 
Structural model presents something, concept ideas that exist in the problem domain, and presents relationships that occur. The structural model is a model of the relationship structure that forms or explains causality between factors. In this research, structural model testing is conducted to find out the relationship between transfer motivation (MT), training retention $(\mathrm{RP})$ on employee performance $(\mathrm{KK})$ through training transfer (TP). A hypothesis can be accepted or declared significant if the value of $t \geq 1,96$. The following is the result of causality calculation from each research variables.

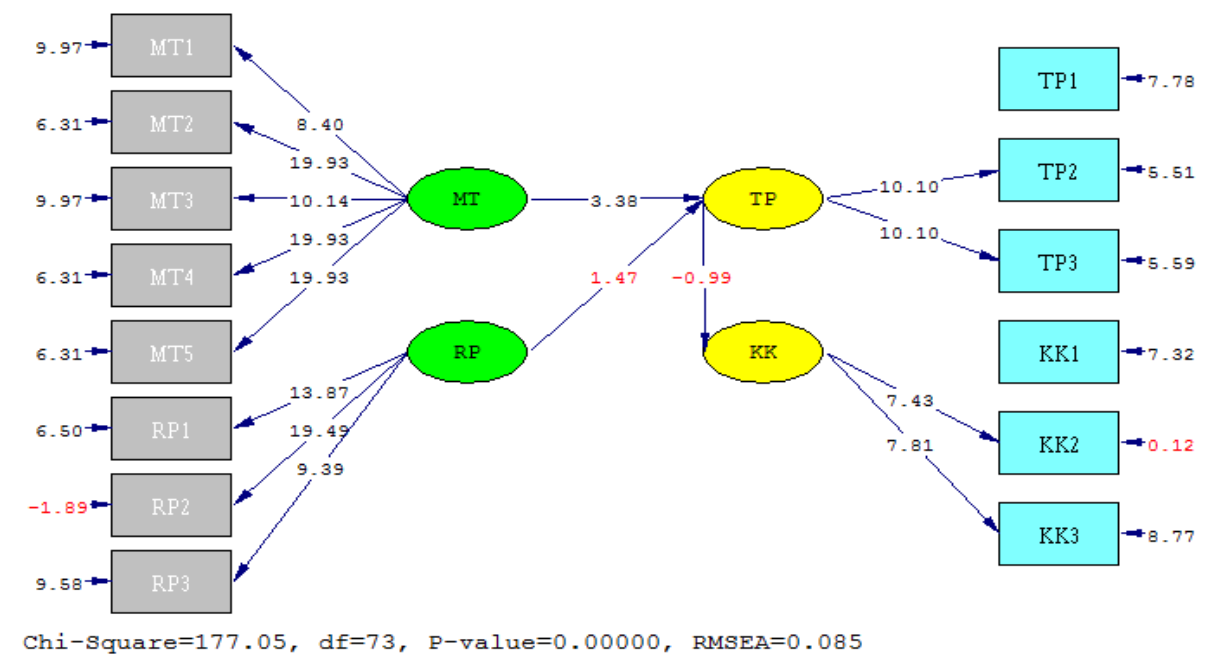

Figure 3 - Structural Equation Model - $t$ Value

Furthermore, from the figures, the researcher can tabulate the data as result of research hypothesis which are as follows:

Table 1 - Result of Research Hypothesis

\begin{tabular}{|c|c|c|c|c|}
\hline Variable Relationship & Estimates & Loading Factor & t Value $(>1,96)$ & Conclusion \\
\hline MT - TP & 0,26 & 0,26 & 3,38 & Significant \\
\hline RP - TP & 0,10 & 0,10 & 1,47 & Not significant \\
\hline TP - KK & $-0,08$ & $-0,08$ & $-0,99$ & Not significant \\
\hline
\end{tabular}

Based on the structural equation model, the t-value of each relationship between latent variables RP - TP and TP - KK are not significant, while MT - TP has value above 1,97 meaning that it is significant. Afterwards, goodness of fit test is conducted to assess whether the data collected fit and match the model. There are three types of measures to test whether the SEM model as a whole fits into fit good data. Sizes and values are outlined in the following table:

Table 2 - Structural Model Match Testing (Goodness of Fit)

\begin{tabular}{|c|c|c|c|}
\hline Size & Description & Value & Conclusion \\
\hline \multicolumn{4}{|c|}{ Absolute Fit Measures } \\
\hline Chi squared & $\geq 0,05$ fit model & 177,05 & Good Fit \\
\hline Goodness of Fit Index (GFI) & $\begin{array}{c}\geq 0,90 \text { fit model, } 0,80 \leq \mathrm{GFI} \leq 0,90 \text { model } \\
\text { marginal fit }\end{array}$ & 0,89 & $\begin{array}{l}\text { Marginal } \\
\text { Fit }\end{array}$ \\
\hline Adjusted goodness of fit index (AGFI) & $\begin{array}{c}\geq 0,90 \text { fit model, } 0,80 \leq \mathrm{AGFI} \leq 0,90 \text { model } \\
\text { marginal fit }\end{array}$ & 0,84 & $\begin{array}{l}\text { Marginal } \\
\text { Fit }\end{array}$ \\
\hline Root Mean Square Residual (RMR) & $\begin{array}{c}\text { Difference between model estimates covariance } \\
\text { matrix, } \geq 0,05 \text { fit model }\end{array}$ & 0,06 & Good Fit \\
\hline Standardized RMR & $\begin{array}{c}\geq 0,05 \text { fit model; } 0,05 \leq \text { SRMR } \leq 0,1 \text { acceptable } \\
\text { fit; } S R M S>0,1 \text { poor fit }\end{array}$ & 0,06 & Good Fit \\
\hline $\begin{array}{l}\text { Root mean square error of } \\
\text { approximation (RMSEA) }\end{array}$ & $\begin{array}{c}\leq 0.05 \text { model of good fit; } 0.05 \leq \text { RMSEA } \leq 0.08 \\
\text { model is quite good }\end{array}$ & 1,08 & Fit \\
\hline $\begin{array}{l}\text { Expected Cross Validation Index } \\
\text { (ECVI) }\end{array}$ & The value is close to 1 good fit model & 1,21 & Good Fit \\
\hline
\end{tabular}


Table 3 - Structural Model Match Testing (Goodness of Fit)

\begin{tabular}{|c|c|c|c|}
\hline Size & Description & Value & Conclusion \\
\hline \multicolumn{4}{|c|}{ Incremental Fit Measures } \\
\hline Normed fir Index (NFI) & $\geq 0,90$ model of good fit & 0,90 & Good Fit \\
\hline Non-normed fit index (NNFI) & $\geq 0,90$ model of good fit & 0,92 & Good Fit \\
\hline Relative fit Index (RFI) & $\geq 0,90$ model of good fit & 0,88 & Marginal Fit \\
\hline Incremental fit Index (IFI) & $\geq 0,90$ model of good fit & 0,94 & Good Fit \\
\hline Comparative fit Index (CFI) & $\geq 0,90$ model of good fit & 0,94 & Good Fit \\
\hline \multicolumn{4}{|c|}{ Parsimony Fit Measures } \\
\hline Akaike information criterion (AIC) & AIC value $<$ model good fit & 241,05 & Good Fit \\
\hline $\begin{array}{l}\text { Consistent goodness of fit index } \\
\text { (CAIC) }\end{array}$ & AIC value $<$ model good fit & 378,60 & Good Fit \\
\hline $\begin{array}{l}\text { Parsimony goodness of fit index } \\
\text { (PGFI) }\end{array}$ & $\begin{array}{c}\text { The value of PGFI> models and ranges from } 0 \\
\text { to } 1\end{array}$ & 0,62 & Good Fit \\
\hline Parsimony normed fit index (PNFI) & The value of PNFI> model and ranges from 0 to & 0,72 & Good Fit \\
\hline
\end{tabular}

From the description of structural model match testing above, it can be concluded that the whole model can be said good or good fit.

Analysis of Causal Relationships. The problem of causality is actually a matter of probability. For instance, how much the probability of decreasing a person's depression after failure in applying training results at work? However, in a developing country like Indonesia, the problem of causality is rarely linked to probability. "Does $X$ affect $Y$ " can be seen from statistical inference and rarely involves causal inference. Analysis of causal relationships is used to determine the causal relationship of each variable, and it can be seen as follows:

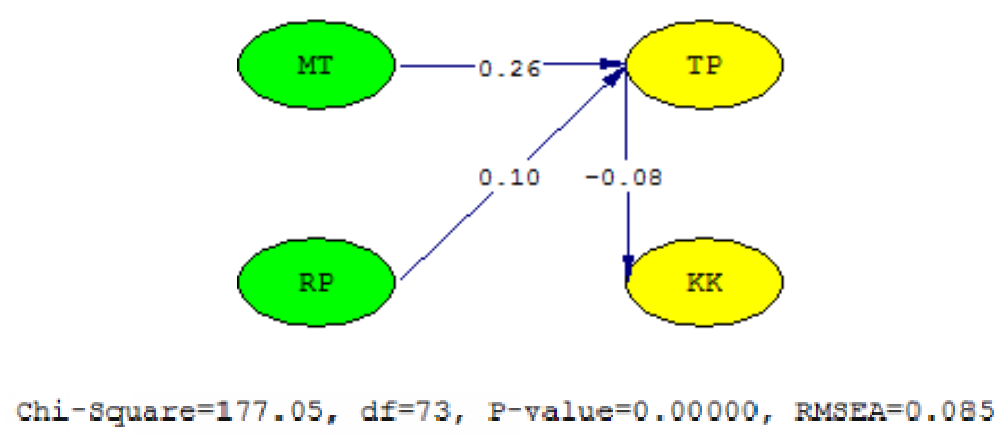

Figure 4 - Path of Causal Relation - t Value

As for the result of calculation of structural equations and reduced form equations, the output of lisrer 8.7 program which is formed automatically at program output can be seen as follows:

Structural Equations:

$$
\begin{gathered}
\mathrm{TP}=0.26^{\star} \mathrm{MT}+0.10^{*} \mathrm{RP}, \text { Errorvar. }=0.92, \mathrm{R}^{2}=0.084 \\
\mathrm{KK}=-0.077^{*} \mathrm{TP}, \text { Errorvar. }=0.99, \mathrm{R}^{2}=0.0059
\end{gathered}
$$

Reduced Form Equations

$$
\begin{gathered}
\mathrm{TP}=0.26^{\star} \mathrm{MT}+0.10^{\star} \mathrm{RP}, \text { Errorvar. }=0.92, \mathrm{R}^{2}=0.084 \\
\mathrm{KK}=-0.020^{\star} \mathrm{MT}-0.0079 * \mathrm{RP}, \text { Errorvar. }=1.00, \mathrm{R}^{2}=0.00050
\end{gathered}
$$

Based on the estimation of research model causal relationships above, the analysis of causal relationship can be done. First, values of t-value and coefficients of structural equations are summarized in the following table: 
Table 4 - Values of $\mathrm{t}$ value and Coefficient of Structural Equation

\begin{tabular}{|c|c|c|c|}
\hline No. & Path & $\begin{array}{c}t \text { Value } \\
(\mathrm{t} \geq 1,96)\end{array}$ & Conclusion \\
\hline 1 & MT - TP & 3,38 & Significant \\
\hline 2 & RP - TP & 1,47 & Not significant \\
\hline 3 & TP - KK & $-0,99$ & Not significant \\
\hline
\end{tabular}

Based on the above table, it can be identified that the coefficient of MT - TP has the absolute $t$ value $\geq 1.96$ which means significant, while the coefficients of RP - TP and TP KK have values of 1.47 and -0.99 below the standard value $(\leq 1.96)$ which mean not significant.

Hypothesis Testing. In this study, there are three hypotheses. Hypothesis testing is done with a significance level of $5 \%$ resulting in a critical $t$ value. The hypothesis is accepted if the value of $t$ is greater or equal to 1,96 and the hypothesis is rejected if the value of $t$ is smaller or equal to 1,96. Based on the value of $t$, hypotheses are tested to see whether the proposed model is supported by the data attached in the following table:

Table 5 - Values of $t$ value and Coefficients of Structural Equation

\begin{tabular}{|c|c|c|c|}
\hline Hypothesis & Path & $\begin{array}{c}\mathrm{t} \text { Value } \\
(\mathrm{t} \geq 1,96)\end{array}$ & Conclusion \\
\hline $\mathrm{H} 1$ & High transfer motivation can improve training \\
transfer & 3,38 & $\begin{array}{c}\text { The data supports the } \\
\text { hypothesis }\end{array}$ \\
\hline $\mathrm{H} 2$ & $\begin{array}{c}\text { High training retention can improve training } \\
\text { transfer }\end{array}$ & 1,47 & The data rejects the hypothesis \\
\hline $\mathrm{H} 3$ & $\begin{array}{c}\text { High training transfer can improve employee } \\
\text { performance }\end{array}$ & $-0,99$ & The data rejects the hypothesis \\
\hline
\end{tabular}

\section{DISCUSSION OF RESULTS}

Motivation Transfer Influences Training Transfer. Based on the result of the table test, it shows that the analysis results support the hypothesis $\mathrm{H} 1$. The calculation result is known that the motivation of transfer has a positive relation to training transfer, with $\mathrm{t}$ value equal to 3,38 bigger than standard value that is $1,96(3,38>1,96)$. The results of this study support the first hypothesis meaning that $\mathrm{H} 1$ is accepted, specifically there is a positive relationship between transfer motivation and training transfer. High transfer motivation can improve training transfer. The results of the analysis indicate that the motivation of transfer consisting of self-preparedness, superiors support, peer support, extrinsic supporting aids in the form of rewards, intrinsic supporting aids in the form of praise on employees affect the transfer of training.

According to Awais Bhatti et al, (2010) the role of readiness of trainees in the training transfer process is based on basic skills to perform different activities during training and basic knowledge of different tasks and needs to be implemented during the training. If the trainee has basic skills, then training activities will be better done. It means that basic skills allow employees to be ready to perform with different training tasks. Peer support is measured by appreciating new skills applied by participants and expectations of the effect of applying these new skills and finding a positive relationship of peer support to transfer of training through transfer motivation (Seyler, 1998). Based on Goldstein and Ford (2002), superior support in the area of training effectiveness is essential in which it functions as a controller for optimizing the use of knowledge and attitudes gained in training (Nijmat, et al., 2006). Supporting aids in the form of intrinsic rewards and extrinsic rewards positively influence the transfer motivation (Tharenou, 2001) where employees do not transfer the skills they learn if they feel this effort does not have impact on their career or remuneration.

The relation with this research is that dimension of the transfer motivation has positive value meaning that the motivation of transfer in PT. Gandum Mas Kencana from participants' readiness factors, peer support, superiors support and supporting aids in the form of intrinsic rewards and extrinsic rewards support training transfers. Furthermore, the positive effect of 
transfer motivation on overall training transfers shows that the planned training to employees, especially the production operators on the regular training materials that have been set cost and schedule to each participant goes according to plan. Preparedness and training as important things to be done with high awareness make the training goes according to plan and fulfills the purpose of the training. Physical conditions such as good vision of the participants, the lighting of the training room and the room setting support to run the training, as well as the participants' sense of speech, to express opinions on things that are not understood. In addition, the opportunity to ask is always given by the trainer at any time with a customized pattern; there is an interactive part where the participants immediately ask when there are things that are not understood and can also provide a special session for the question at the end of each material. Distributed long-distance schedules to participants have a positive impact on where they prepare for the exam both before the training and after the training and this also gives participants confidence to challenge the test results with their own ability. The material given after the training to the participants is also a positive thing in which employees re-read the material when they apply it in the workplace. Training for employees at PT. Gandum Mas Kencana not only becomes a regular agenda, but also it is expected by employees to improve their competence in knowledge, skills, and attitudes that must be aligned with the demands of the organization.

Training Retention does not Influence Training Transfer. Based on the results of data analysis, the results of this study reject the second hypothesis which means that $\mathrm{H} 2$ is rejected. From the data that has been analyzed by the researcher, the calculation results are known that training retention has a value below the standard $t$ value which is smaller than the standard $t$ value. The value obtained in this study amounted to 1,47 which is smaller than the default value of 1,96. It indicates that training retention in PT. Gandum Mas Kencana does not have significant influence on the training transfer process.

According to Velada, et al., (2007) the concept of training retention is similar to cognitive abilities and explains the extent to which trainees retain content/material after the training is completed. Training retention is an important factor in undertaking training transfer in which the more trainees understand the content/materials; the more helpful they are for companies to improve employee knowledge and skills without having to repeat the same thing. It can hamper the provision of new training materials for employees and wastage of costs occurs. On the other hand, it can also create a cadre of trainers who can lower this knowledge around them. It becomes something that is very profitable for the organization if it can run.

The results reject the hypothesis mean that there is a weakness of the employees on the retention of training in the form of remembering the training materials that have been executed, can easily answer questions about the content of material that has been studied and the material studied should be repeated in the same year because the test after the training has a value below the standard (exam score $<70$ ) or failing to pass the training exam on the material at PT.Gandum Mas Kencana, as it relates to company policy that is less concerned with this. The absence of punishment or reward for participants who do not enforce predetermined rules against training retention is there as well.

One of the important things to see employees' success in training retention in remembering the material that has been given is to randomly ask the employees about the material content theoretically and they are able to answer it well, as Indonesian citizens who are asked to mention one of the principles of Pancasila, because we have studied from elementary school and it continues to be repeated, then automatically if the question arises about this matter, a responsive response is directly given. That is the measure of an employee's success towards the mastery of material that has been given. Employees who have received training are expected to easily answer what they have learned, especially in informal situations where the material has become very inspiring to them, let alone this material is repeated every year as compulsory materials of ISO 9001: 2008 on management quality and ISO 22000: 2005 food safety.

Training Transfer does not Influence Employee Performance. Based on the results of the analysis test in Table 5-54, it is described that the third hypothesis or $\mathrm{H} 3$ is also rejected. 
High training transfer cannot improve employee performance. Based on data that have been analyzed by the researcher, the result of the calculation can be known that the training transfer has a significant positive relation on employee performance, with the value of $t=-$ 0,99 smaller than the standard $t$ value of 1,96. It explains that strong training transfers do not influence employee performance, as employee performance measurement focuses more on concrete matters such as sales and production capacity. The trainings are provided only as an obligation to meet internal or external audit standards or requirements. When an employee conducts training transfer in his workplace, the employee feels unlikely to have the opportunity to demonstrate the abilities and skills he has acquired during training with good preparedness, open colleagues support, superior support, and intrinsic and extrinsic supporting aids.

Superiors are satisfied with the performance shown by their subordinates to increase productivity, but it has not been an annual assessment or as KPI where individually they apply the abilities and skills provided in practice, when the spread of training participants to the material is evenly distributed and every employee runs it in the workplace automatically produces increased work productivity, if translated in HACCP and GMP material results, employee errors decline due to knowing the procedures established by the system in handling production to obtain a good product.

The quality of work provided also increases where the application that occurs directly corrects wrong patterns of evaluation of the application by employees at the workplace. This report becomes a datum that should be considered by superiors to take steps to improve the production process in order to create good and standardized products that have been determined. Implementation performed by each employee is sometimes able to exceed the capacity expected by superiors and company. The details of the untouched and the big impact make the employee able to contribute above his or her task and exceed expectations. It is very good for the company in increasing the sales profit in which indirectly the things that cannot be drawn can be found by employees at the time of implementation of training results in the workplace.

Employees who have experienced training and applied the training to their workplaces can also complete the work in a timely manner as they are happy to work from the results of implementing their own training. It is positive for organizations where they have the drive to get the job done and continue to apply good training results for the company's business development with super-quality products. Implementation of training results also increase employee cooperation because to perform successful implementation, they must cooperate with each other since the production line is the part that constitutes a unity called production system. Implementation without cooperation from employees will not be seen if done partially. Precisely, it is a major problem when this application is implemented in part because it will not reach the maximum point in its implementation and it can damage the existing system. Cooperation is needed to establish new methods of applying training results. If the results of one material are thoroughly implemented, the result will increase work productivity and will automatically improve employee performance. Employee performance refers to the ability of employees in performing the overall tasks that become their responsibility. The performance of employees will increase if they actively involve, participate, and become the parts of the team in the process of the activities of the organizational unit where they work.

Managerial Implications. The programs that will be run are adjusted to the results of the research in which the motivation of transfer influences the transfer of training, but the retention of training does not have influence on training transfer and training transfer does not have influence on employee performance. The researcher will describe the managerial implications that have only influence which motivation transfer to training transfer. Transfer motivation supported by participants' readiness, peer support, superior support and supporting aids in the form of intrinsic rewards and extrinsic rewards have an influence on training transfer that defines the extent to which employees apply the results of their workplace training and have a positive influence on employee performance at PT. Gandum Mas Kencana. The superior can support the participants/subordinates after the training by 
providing literature to solve problems faced by the participants in terms of applying the skills learned in the workplace. In addition, the superior may discuss different methods of applying the skills learned at the workplace and set goals to encourage employees to use training on the job. Finally, this study argues that if the superior plays his role effectively, the transfer of training can be increased again and continuously according to how much the role played by the superior to achieve the company's goals related to the implementation of the training results provided.

Referring to the support of colleagues in the training transfer process, this study suggests that colleagues may also play their role to maximize training transfer. Colleagues should encourage participants to participate in training activities and assist trainees to apply workplace learning skills in order to improve performance and to achieve organizational tasks. In addition, colleagues should give appreciation, when they use training on their work, rewards and encouragement motivate participants to use training on the job. Finally, colleagues expectations of the trainees also play an important role in training transfer. The expectations of colleagues in terms of using job training also motivate participants to apply the skills learned in the workplace.

Another important consideration for corporate trainers is that employees should be ready to participate in training activities. The findings of this study suggest that prior to starting the training program, it should be made sure that the trainee has the basic skills and knowledge to participate in the training activities. It is because knowledge and skills about training activities motivate participants to take parts in training activities for the transfer of skills learned in the workplace. For example, if employees will learn about a good food handling system, it is important for employees to have HACCP and GMP knowledge and skills to operate the machine as well as the meaning of the system symbols. If employees lack knowledge of HACCP and GMP, it will be difficult for employees to actively participate in training activities and maximize learning. In conclusion, superiors and trainers should provide basic skills to employees who help them to demonstrate training tasks and actively participate in training activities. Therefore, learning is better during training because it will motivate the trainees to transfer training on the job.

Human resource development and trainers should explain practically to participants with the model and characteristics of trainees, as it concerns how they can apply the skills learned in the workplace and increase the success rate of trainees leading to training transfers. Therefore, the trainer should provide more practical examples during the training sessions by helping the trainees understand how the training is closely related to their work. Therefore, using real-life examples and day-to-day work can build participants' confidence and motivate them to transfer training to the job. In addition, top management, coaches, and superiors should appreciate, encourage, and motivate participants to take parts in training activities.

The factors that need to be considered to improve the transfer of training is how much improvement preparation should be done by employees in training, the extent of involvement of colleagues in implementing the training that has been run, how much support of superiors to provide space and employee freedom in applying training that has been accepted in the workplace, and how important rewards for employees who want to apply workplace training. The following part describes the influence of transfer motivation on training transfer.

\section{CONCLUSION}

Based on the results of the research analysis, the discussion and the description in the previous chapters, the conclusions are obtained: 1) the transfer motivation has a positive influence on the training transfer, where strong self-motivation, support from superiors and colleagues can increase the activity of training transfer in the workplace. It has an influence on improving employee performance, 2) training retention in the form of reward for intrinsic reward in the form of praise, reward; and extrinsic reward in the form of material or money, career as a reward do not positively influence the employee's performance in implementing the results of the training they have obtained as one of the ways to improve the ability to 
achieve the rewards/incentives provided by the organization. In this research, the influence given is weak so if in their transfer motivation is high, then it must be conducted repeatedly to maintain the given materials. It means that employees at PT. Gandum Mas Kencana has the drive to do the training to apply the training results, but it is less concerned if asked to maintain the training by remembering the material theoretically. It is clear that employees prefer practicing directly in the field to textbook theory, 3) training transfer has a positive influence on employees and organizations in which employees contribute by applying training provided to them to improve employee performance.

\section{REFERENCES}

1. Awais Bhatti, M. (2013) Transfer of training: does it truly happen? An examination of support, instrumentality, retention and learner readiness on the transfer motivation and transfer of training. European Journal of Training and Development, 37(3), 273-297.

2. Baldwin, T. T., \& Ford, J. K. (1988). Transfer of training: A review and directions for future research. Personnel Psychology, 41: 63-105.

3. Colquitt J. (2000). Toward an integrative theory of training motivation: A meta-analytic path analysis of 20 years of research. Journal of Applied Psychology, Vol. 85(5), Oct 2000, 678-707.

4. Crider, Andrew B, (2003).Psychology. Scott, Foresman \& Company.

5. Malhotra. (2010). Marketing Research: An Applied Orientation Sixth Edition Pearson Education.

6. Smith, Jentsch KA., Salas, E, \& Brannick, MT. (2001). To transfer or not to transfer? Investigating the combined effects of trainee characteristics, team leader support, and team climate. J Appl Psychol, 86(2):279-92.

7. Sugiyono. 2012. Metode Penelitian Kuantitatif Kualitatif dan R\&D. Bandung: Alfabeta.

8. Sulistyohadi T, (2002), Beberapa Isu Penting Dalam Program Pelatihan Dan Pengembangan Sumber Daya Manusia, Majalah Manajemen \& Usahawan Indonesia, Lembaga Manajemen FE -UI,No. 05 TH), pp. 11-14.

9. Tziner, A. and Haccoun, R.R. (1991) Personal and Situational Characteristics Influencing the Effectiveness of Transfer of Training Improvement. Journal of Occupational Psychology, Vol. 64: pp. 167-177. 